\title{
Precipitation response to regional radiative forcing
}

\author{
D. T. Shindell, A. Voulgarakis, G. Faluvegi, and G. Milly \\ NASA Goddard Institute for Space Studies and Columbia Earth Institute, New York, USA \\ Correspondence to: D. T. Shindell (drew.t.shindell@ nasa.gov)
}

Received: 20 January 2012 - Published in Atmos. Chem. Phys. Discuss.: 13 February 2012

Revised: 25 May 2012 - Accepted: 16 July 2012 - Published: 2 August 2012

\begin{abstract}
Precipitation shifts can have large impacts on human society and ecosystems. Many aspects of how inhomogeneous radiative forcings influence precipitation remain unclear, however. Here we investigate regional precipitation responses to various forcings imposed in different latitude bands in a climate model. We find that several regions show strong, significant responses to most forcings, but that the magnitude and even the sign depends upon the forcing location and type. Aerosol and ozone forcings typically induce larger responses than equivalent carbon dioxide $\left(\mathrm{CO}_{2}\right)$ forcing, and the influence of remote forcings often outweighs that of local forcings. Consistent with this, ozone and especially aerosols contribute greatly to precipitation changes over the Sahel and South and East Asia in historical simulations, and inclusion of aerosols greatly increases the agreement with observed trends in these areas, which cannot be attributed to either greenhouse gases or natural forcings. Estimates of precipitation responses derived from multiplying our Regional Precipitation Potentials (RPP; the response per unit forcing relationships) by historical forcings typically capture the actual response in full transient climate simulations fairly well, suggesting that these relationships may provide useful metrics. The strong sensitivity to aerosol and ozone forcing suggests that although some air quality improvements may unmask greenhouse gas-induced warming, they have large benefits for reducing regional disruption of the hydrologic cycle.
\end{abstract}

\section{Introduction}

Precipitation projections vary substantially between models in many regions (Meehl et al., 2007). While most of the divergence may be due to differing representations of physical processes, some of the intermodel differences may arise from inhomogeneous forcing by aerosols and ozone, as these forcings vary greatly across models. Studies suggest that hemispherically asymmetric forcing perturbs tropical rainfall (Chung and Seinfeld, 2005; Rotstayn and Lohmann, 2002; Takemura et al., 2005; Ming and Ramaswamy, 2009), and that aerosols affect Sahel precipitation (Ackerley et al., 2011; Biasutti and Giannini, 2006; Rotstayn and Lohmann, 2002; Kawase et al., 2011; Chang et al., 2011) and the Asian monsoon (Ramanathan et al., 2005; Meehl et al., 2008; Wang et al., 2009; Bollasina et al., 2011; Shindell et al., 2012). Hence it is important to understand the link between the location and type of radiative forcing and the precipitation response. Additionally, virtually all comparisons of the impact of multiple forcing agents in emissions trading schemes or evaluation of mitigation scenarios use metrics based on global mean forcing (Shine et al., 2005; Fuglestvedt et al., 2010). Thus it is important to know how global mean forcing relates to precipitation response for inhomogeneous forcing agents. We therefore examined the precipitation response in simulations driven by historical individual forcings and by forcing localized within particular latitude bands. We hope that this initial study can provide insight into possible methods for studying precipitation response to localized forcing and perhaps encourage multi-model intercomparison to characterize the robustness of these relationships.

\section{Climate modeling and analysis methodology}

We examined transient GISS simulations for 1880-2003 using the Climate Model Intercomparison Project (CMIP3) version of the GISS-ER coupled ocean-atmosphere model with individual forcings by well-mixed greenhouse gases (WMGHG), ozone, tropospheric aerosol direct effects (ADE), tropospheric aerosol indirect effects (AIE), and all forcings (ALL; also including land use, solar and volcanic forcings) (Hansen et al., 2007b). For these simulations, we 
report area-averaged regional trends using the mean of a fivemember ensemble, where each simulation differs only in its initial conditions. Trends are calculated using linear regression on the ensemble-mean precipitation at each point, with points then averaged together. Uncertainties are assessed using an analogous five-member control ensemble of simulations to quantify internal variability levels, with uncertainties for a particular regional average based on the standard deviation of trends across all the points within a region. In other words, each location is essentially treated as an independent measurement of internal variability that goes into the regional average (though as neighboring points may be related, we in fact assume $n / 2$ degrees of freedom where $n$ is the number of points within a region and $n / 2$ roughly accounts for the modeled autocorrelation between points).

We concentrate analyses on May through September, when absolute precipitation responses are typically greatest over Northern Hemisphere (NH) land areas (see Appendix A for October to April results). Model results are compared with precipitation observations taken from a gridded dataset that has been optimized for analysis of temporal trends (Hulme et al., 1998). Trends are mean linear regressions over locations with at least 3 of the 5 months having data for a particular year and at least $2 / 3$ of years having data. Results are robust to reasonable changes in these limits. Uncertainties are based on the variability of trends across points as in the analysis of modeled trends (again using 1-sigma values and assuming $n / 2$ degrees of freedom where $n$ is the number of points within a region).

We also performed a set of simulations with the identical model configuration imposing forcing in discrete latitude bands (Shindell and Faluvegi, 2009): the tropics $\left(30^{\circ} \mathrm{S}-\right.$ $\left.30^{\circ} \mathrm{N}\right)$, $\mathrm{NH}$ mid-latitudes $\left(30^{\circ} \mathrm{N}-60^{\circ} \mathrm{N}\right)$, the Arctic $\left(60^{\circ} \mathrm{N}-\right.$ $\left.90^{\circ} \mathrm{N}\right)$ and the Southern Hemisphere extratropics $\left(30^{\circ} \mathrm{S}-\right.$ $90^{\circ} \mathrm{S}$ ). These bands have generally faster atmospheric mixing within them than across their boundaries, and hence regional emissions of short-lived species and their precursors have their greatest impact on radiative forcing within these areas. Furthermore, the temperature response to forcing occurs primarily within $\sim 30$ degrees in latitude but extends very far in longitude (Shindell et al., 2010). Analyses of results localized at particular longitudes would also be useful, however, especially for precipitation, which could be more sensitive to local changes than is surface temperature.

Equilibrium climate simulations were performed examining the response to individual forcings imposed over either a single one of the indicated latitude bands or a combination of bands. The forcings used were increases in $\mathrm{CO}_{2}$ and black carbon (BC), and decreases in sulfate (representative of reflective aerosols) and tropospheric ozone. As there has been very little forcing from tropospheric aerosols or ozone in the Southern extratropics, only forcing from $\mathrm{CO}_{2}$ was imposed in that band. Localized $\mathrm{CO}_{2}$ forcing is as an idealized case for illustrative purposes and to aid mechanistic understanding only, as of course such a forcing is unrealistic. When
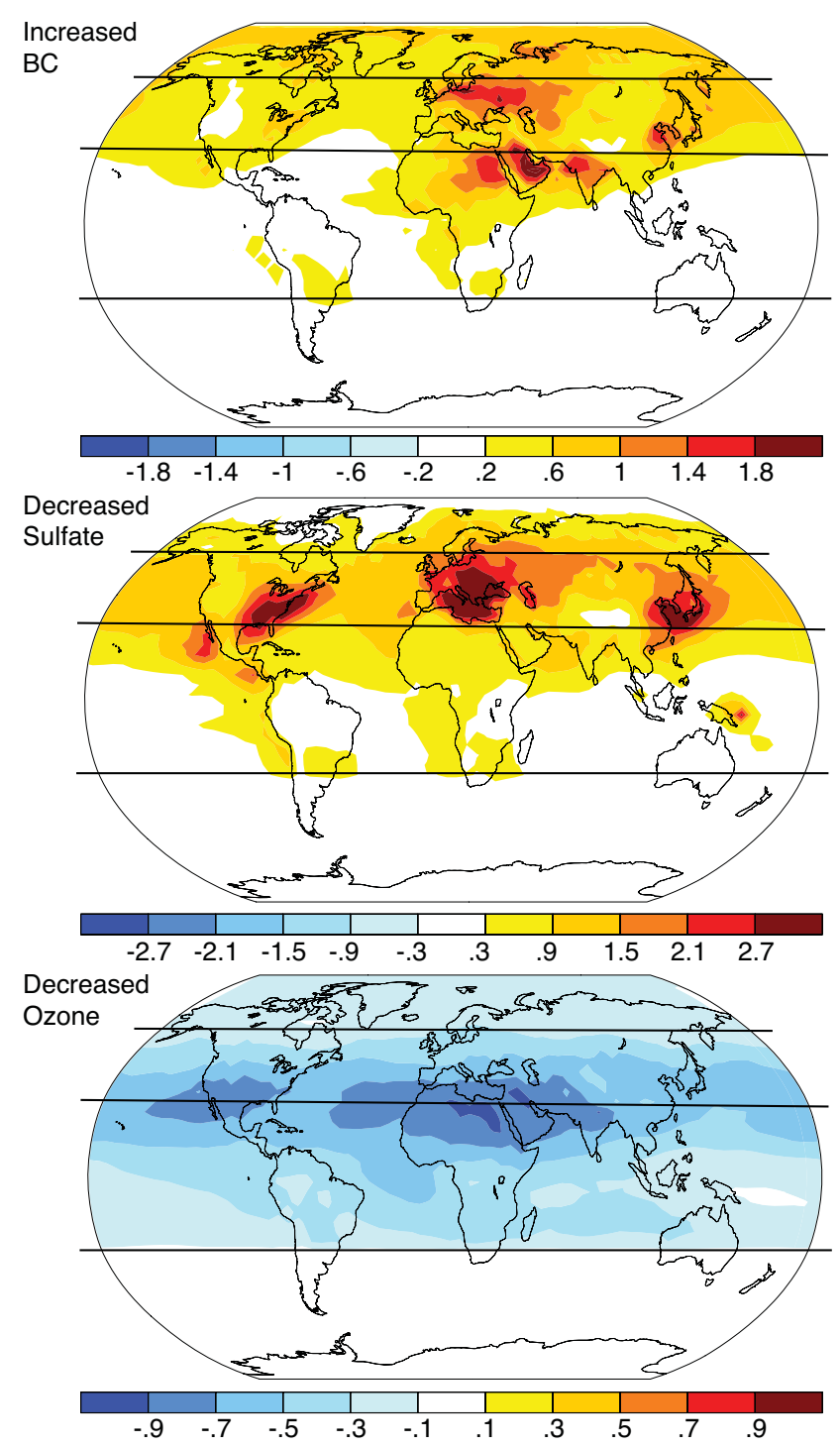

Fig. 1. Spatial patterns of imposed inhomogeneous radiative forcings ( $\mathrm{W} \mathrm{m}^{-2}$ at the tropopause). Forcing were imposed with these spatial structures both within individual latitude bands indicated by the horizontal lines at 30 and 60 degrees or in multiple bands.

we imposed forcing in multiple bands to test the linearity of the response in comparison with the sum of responses to the individual band forcings, we also followed historical patterns. Hence we examined aerosol forcing from $30^{\circ} \mathrm{S}-90^{\circ} \mathrm{N}$ while for $\mathrm{CO}_{2}$ we examined the response to forcing at all latitudes. All forcings were imposed by scaling present-day distributions, so that the aerosol and ozone forcings have a spatial structure within the bands comparable to historical changes. The spatial pattern of the applied forcing is illustrated in Fig. 1. Spatial variations clearly reflect both the locations of emissions and geographic differences in physical factors such as the underlying surface albedo. Scaling was performed uniformly within the bands, with values chosen 

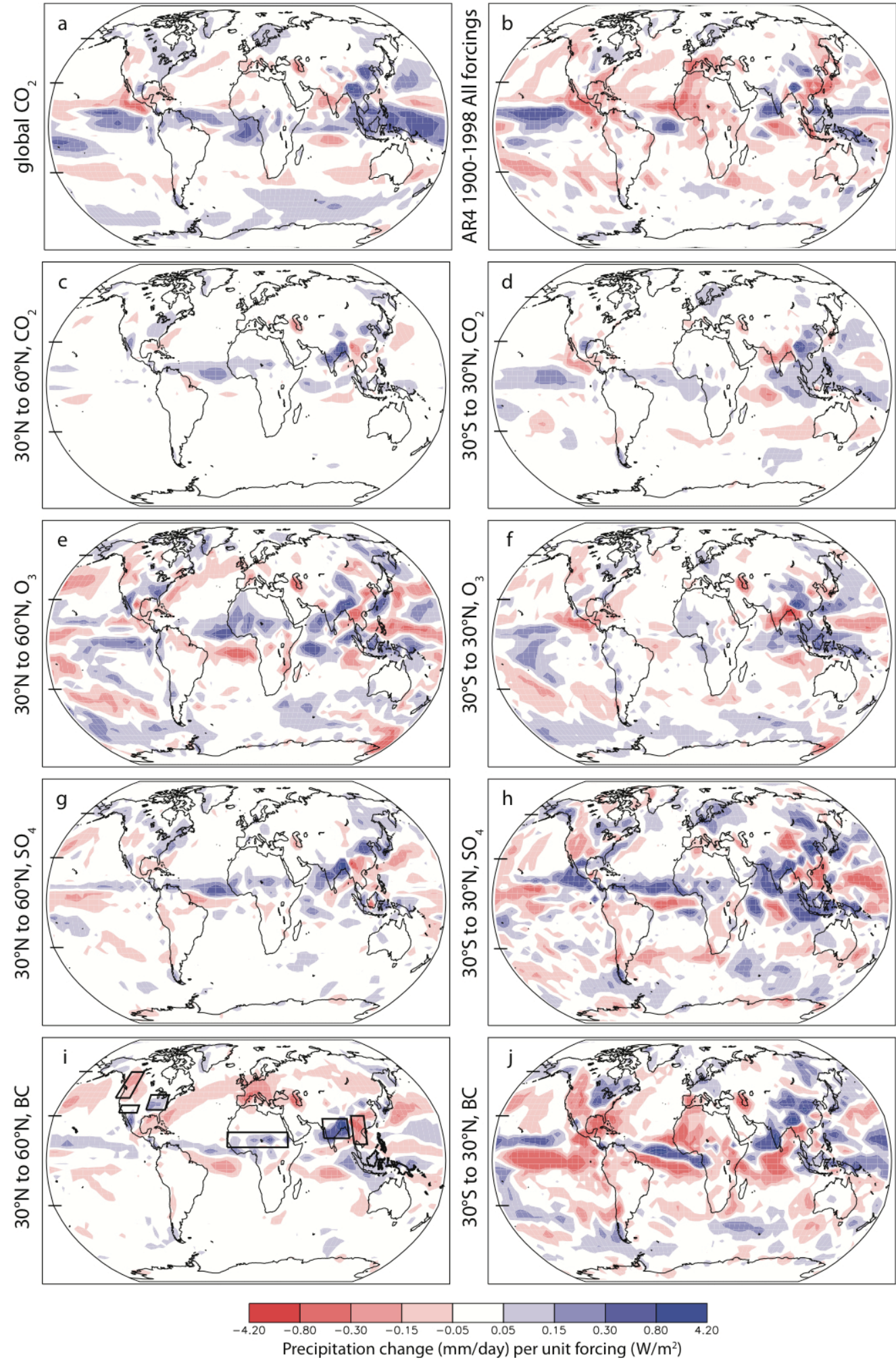

Fig. 2. June-July-August average precipitation change $\left(\mathrm{mm} \mathrm{day}^{-1}\right)$ per unit positive forcing within the given band $\left(\mathrm{W} \mathrm{m}^{-2}\right)$. Forcings are imposed only in the areas listed (the historical simulation includes global forcing). Tick marks indicate $30^{\circ} \mathrm{S}, 30^{\circ} \mathrm{N}$ and $60^{\circ} \mathrm{N}$. Regional analysis, including statistical significance, is presented in Figs. 3 and 4, for the areas shown in panel (i), which are: India/Bangladesh ( $71^{\circ} \mathrm{E}$ to $94^{\circ} \mathrm{E}, 15^{\circ} \mathrm{N}$ to $\left.28^{\circ} \mathrm{N}\right)$, Southwest China/SE Asia $\left(98^{\circ} \mathrm{E}\right.$ to $110^{\circ} \mathrm{E}, 11^{\circ} \mathrm{N}$ to $\left.30^{\circ} \mathrm{N}\right)$, Southwestern $\mathrm{US}\left(120^{\circ} \mathrm{W}\right.$ to $103^{\circ} \mathrm{W}, 32^{\circ} \mathrm{N}$ to $\left.37^{\circ} \mathrm{N}\right)$, Eastern US $\left(95^{\circ} \mathrm{W}\right.$ to $77^{\circ} \mathrm{W}, 34^{\circ} \mathrm{N}$ to $\left.44^{\circ} \mathrm{N}\right)$, the Pacific Northwest $\left(129^{\circ} \mathrm{W}\right.$ to $115^{\circ} \mathrm{W}, 42^{\circ} \mathrm{N}$ to $\left.60^{\circ} \mathrm{N}\right)$, and the $\mathrm{Sahel}\left(17^{\circ} \mathrm{W}\right.$ to $38^{\circ} \mathrm{E}, 9^{\circ} \mathrm{N}$ to $19^{\circ} \mathrm{N}$ ). 
to give forcings large enough in amplitude to provide a clear response (scaling factors ranged from 0.2 to 2.0, yielding at least $0.2 \mathrm{~W} \mathrm{~m}^{-2}$ local forcing within the band in all cases).

Simulations were integrated for $120 \mathrm{yr}$, with analysis using area-weighted means over the last $80 \mathrm{yr}$ following stabilization of the climate. Initial conditions are from a 900yr control run with this model. Significance levels (1-sigma) are calculated relative to the unforced variations seen in 80yr segments of that control run. At the regional level, this method yields uncertainties that are nearly always about half those obtained based on the spatial variation of trends across boxes with the regions. A narrower uncertainty range in the long equilibrium simulations, which supply many realizations of the response to the imposed change, in comparison with the uncertainty range calculated for the single realization of transient changes in the historical runs or observations is quite sensible. Aerosol perturbation experiments were run both with and without a simple parameterization for the AIE that allows aerosols to affect cloud lifetime only (Hansen et al., 2007b). The response to aerosol forcings applied in individual latitude bands tended not to be significantly different if the AIE were included. The Asian response for several cases was larger, but not significantly so (see below for further discussion). Hence responses for localized aerosols are shown for simulations without AIE to allow comparison with historical ADE simulations.

To compare the effects of the various forcings on a common scale, precipitation anomalies are normalized by the average radiative forcing applied within the forcing area. We use the adjusted radiative forcing (allowing stratospheric temperatures only to respond) at the tropopause in all cases except for the AIE runs where fixed-SST forcing including tropospheric response is used, since forcing without tropospheric adjustment is not defined for at least portions of the AIE (including the cloud lifetime effect simulated here). The normalization allows forcings imposed over areas of different size to be sensibly compared. The standard deviation is also normalized by this radiative forcing value to maintain the model's true signal-to-noise ratio.

\section{Results}

We first present analysis of the response to individual localized forcings. We then analyze the response in the historical transient simulations, using the insights gained from the individual, localized forcing runs to inform our interpretation of the historical simulations.

\subsection{Large-scale precipitation response to localized forcings}

The spatial patterns of precipitation responses to global $\mathrm{CO}_{2}$ increases (Fig. 2a) provides a baseline for our analysis. They are almost identical to the response to long-term projections

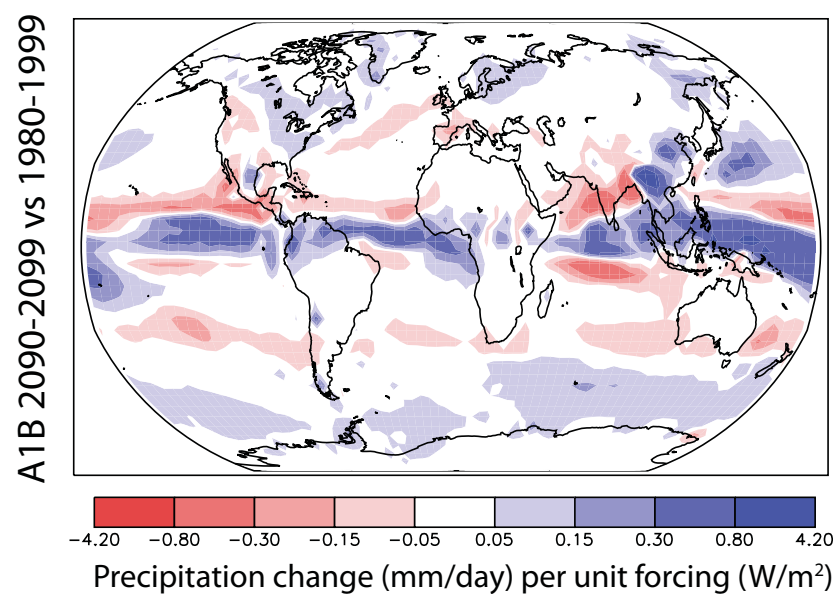

Fig. 3. Ensemble mean June-July-August average precipitation change $\left(\mathrm{mm} \mathrm{day}^{-1}\right)$ per unit positive forcing $\left(\mathrm{W} \mathrm{m}^{-2}\right)$ for the GISS-ER projections driven by A1B scenario concentrations and emissions (Hansen et al., 2007a).

under the A1B scenario (Fig. 3), unsurprisingly as that projection is dominated by $\mathrm{CO}_{2}$ forcing at century timescales. In both the GISS model and the mean of the CMIP3 models (Meehl et al., 2007), boreal summer precipitation increases in a band just north of the equator while generally decreasing in the subtropics. Precipitation also increases at high latitudes. Both these features stem from well-understood physics and are robust across climate models (Meehl et al., 2007; Held and Soden, 2006). The GISS model also reproduces many regional trends that are consistent in sign in $>$ $90 \%$ of CMIP3 models, including decreased precipitation in the Mediterranean, the Pacific Northwest, the Southwestern US/Northwest Mexico, and along the North Atlantic storm track, suggesting that the precipitation response to globally uniform forcing is reasonable. In South and East Asia, the Sahel, and the Eastern US, however, the CMIP3 models were less consistent in the sign of the precipitation changes.

The precipitation response pattern for idealized tropical $\mathrm{CO}_{2}$ increases is similar to the global case, though magnitudes are often smaller (Fig. 2a, d). In contrast, $\mathrm{NH}$ mid-latitude $\mathrm{CO}_{2}$ increases induce an opposite response of the South Asian monsoon and over Northwestern Mexico (Fig. 2a, c) and have little effect on the Southern extratropics.

Tropical ozone forcing causes a generally similar precipitation response pattern to tropical (or global) $\mathrm{CO}_{2}$, though there are differences in the tropical Atlantic and in the Southern extratropics. Responses typically have a larger magnitude, especially within the tropics (Fig. 2d, f). In contrast, tropical sulfate or BC (Fig. $2 \mathrm{~h}, \mathrm{j}$ ) induce quite different responses than global or tropical $\mathrm{CO}_{2}$ in most of the tropics (though the extratropical pattern is typically similar). In particular, the South Asian monsoon shifts west instead of east, and the Sahel dries in response to increased tropical BC. Responses are also stronger for equivalent tropical sulfate or BC 

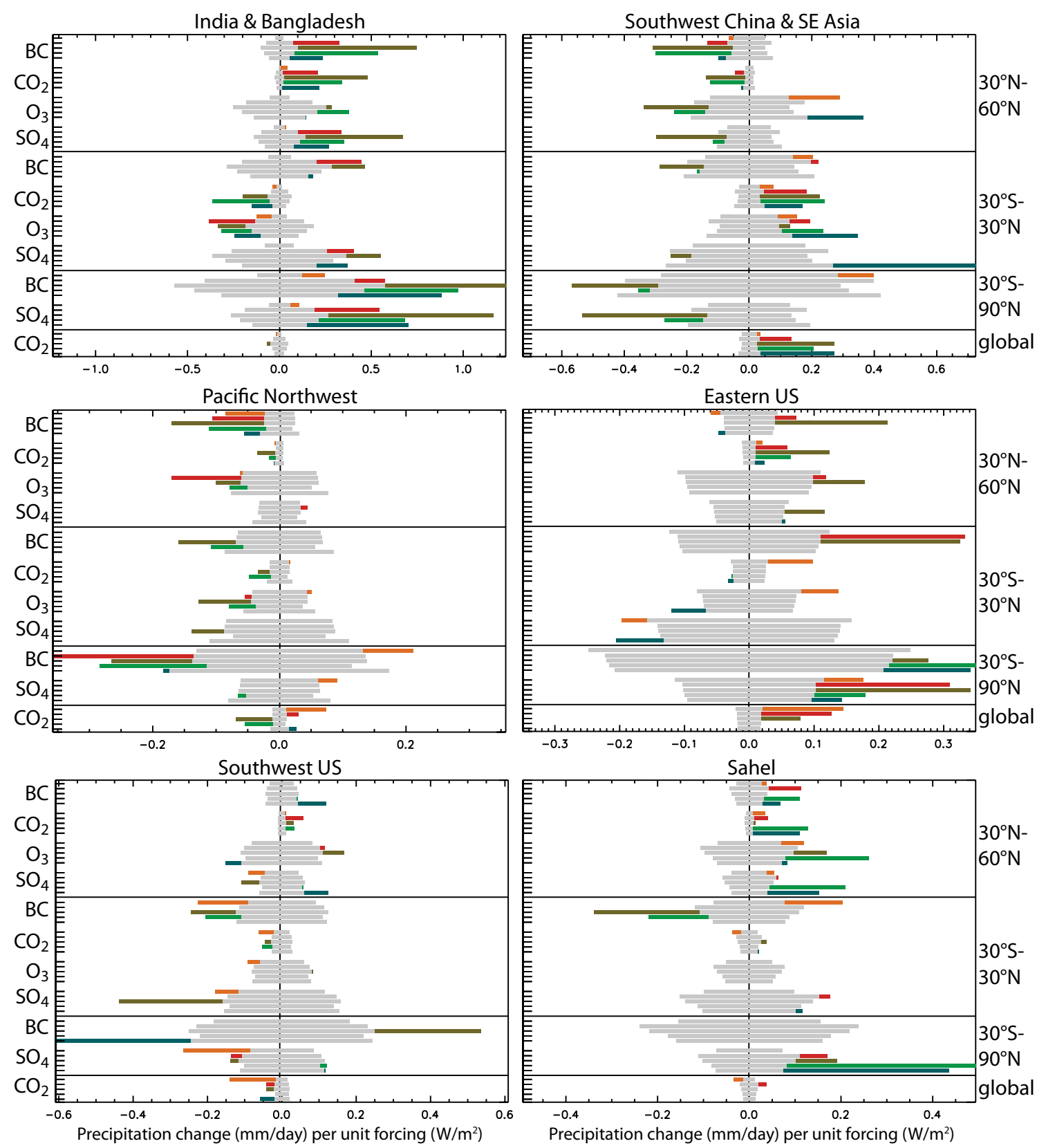

Fig. 4. Monthly mean precipitation responses $\left(\mathrm{mm} \mathrm{day}^{-1}\right)$ to regional and global forcings per unit forcing within the given band $\left(\mathrm{W} \mathrm{m}^{-2}\right)$. Forcing agent is indicated on the left while the location of forcing is indicated on the right. Individual sets of bars show results for May, June, July, August and September (top to bottom). Colored values are statistically significant as compared with the 1-sigma variability in the unforced control run (gray areas).

forcing than for tropical $\mathrm{CO}_{2}$ or ozone. $\mathrm{NH}$ mid-latitude sulfate or $\mathrm{BC}$ forcing, however, produces a response similar to that produced by $\mathrm{NH}$ mid-latitude $\mathrm{CO}_{2}$, though again with enhanced magnitude (Fig. 2c, g, i). Interestingly, $\mathrm{NH}$ midlatitudes are generally more sensitive to tropical than to local sulfate or BC, and parts of the tropics are more sensitive to NH mid-latitude than to local ozone. The tropics generally show high sensitivity to forcing located either in the tropics or at $\mathrm{NH}$ mid-latitudes, though for $\mathrm{CO}_{2}$ and aerosols sensitivity is greater to local forcing. We note that the historical response (Fig. 2b) shows large shifts in the tropics, e.g. in the location of the Inter Tropical Convergence Zone (ITCZ), that seem most consistent with the responses to positive $\mathrm{CO}_{2}$ and/or negative sulfate forcing (comparison with historical trends is discussed in more detail in Sect. 3.3). 

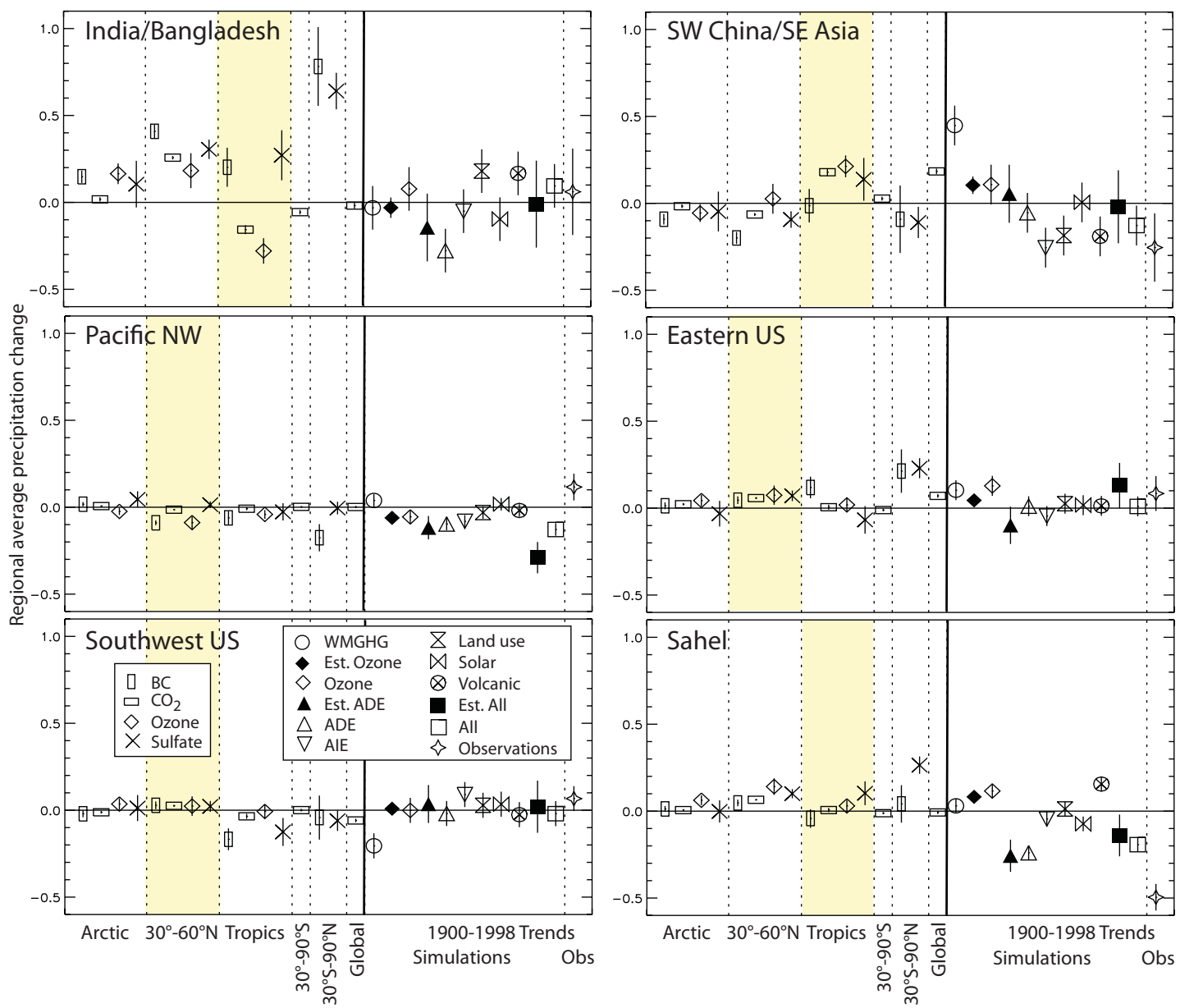

Fig. 5. Precipitation sensitivities (left of solid vertical line) and 1900-1998 historical trends (right of solid vertical line) by region. Values are May-September averages, given as changes per unit tropopause forcing within the band indicated on the $\mathrm{x}$ axis for sensitivities (mm day ${ }^{-1}$ per $\mathrm{W} \mathrm{m}^{-2}$ ) and total trend $\left(\mathrm{mm} \mathrm{day}^{-1}\right)$ for historical simulations. Background shading indicates forcing applied in area where precipitation response is analyzed. Estimated responses ("Est"; solid symbols) are the sum of the model's historical forcing times the response per unit forcing for each agent and region (using the response to sulfate to represent all reflective aerosols). ADE is tropospheric aerosol direct effects and AIE is tropospheric aerosol indirect effects. Obs = observations from (Hulme et al., 1998).

\subsection{Regional precipitation response to individual forcings}

We concentrate on six regions with substantial, coherent boreal summer precipitation anomalies in several experiments (see Fig. 2i). Positive forcing at Northern middle or high latitudes by any agent produces a shift of rainfall away from Southwest China/Southeast Asia (SE Asia hereafter) and into India/Bangladesh (Figs. 4 and 5). Local tropical BC or sulfate produces an opposite response in India/Bangladesh compared with tropical $\mathrm{CO}_{2}$ or ozone, however. Thus local and remote $\mathrm{BC}$ and sulfate positive forcing both increase India/Bangladesh precipitation, while local and remote $\mathrm{CO}_{2}$ and ozone offset one another, making summer precipitation, which occurs primarily via the monsoon, highly sensitive to aerosol forcing in this region in our model. Note that the responses are usually consistent across the months of the wet season (Fig. 4). The influence of surface forcing, which can affect Asian precipitation (Wang et al., 2009; Ramanathan and Carmichael, 2008; Meehl et al., 2008), could account for the different response to aerosols versus greenhouse gases.

SE Asia precipitation responds most strongly to local $\mathrm{CO}_{2}$ and ozone, and remote $\mathrm{BC}$. Responses per unit tropopause forcing are similar for remote $\mathrm{CO}_{2}$, ozone and sulfate and typically opposite to responses to local forcing. The response to Southern Hemisphere extratropical $\mathrm{CO}_{2}$ forcing is comparatively small. Per unit surface forcing, responses vary greatly across forcing agents in all regions where forcing is imposed (Table 1; for these and other response areas), suggesting that change per unit surface forcing is a less useful metric for evaluating precipitation response. Hence hereafter responses are solely analyzed relative to tropopause forcing.

For North America, local positive forcing by any agent leads to a drier Pacific Northwest (NW) and wetter Eastern 
Table 1. May-September average precipitation changes per unit forcing (tropopause or surface) within the indicated band (mm day ${ }^{-1}$ per $^{-}$ $\left.\mathrm{W} \mathrm{m}^{-2}\right)$.

\begin{tabular}{|c|c|c|c|c|}
\hline $\begin{array}{l}\text { Forcing agent } \\
\text { and location }\end{array}$ & $\begin{array}{l}\text { India/ } \\
\text { Bangladesh, } \\
\text { tropopause } \\
\text { forcing }\end{array}$ & $\begin{array}{c}\text { India/ } \\
\text { Bangladesh, } \\
\text { surface } \\
\text { forcing }\end{array}$ & $\begin{array}{l}\text { SW China/ } \\
\text { SE Asia, } \\
\text { tropopause } \\
\text { forcing }\end{array}$ & $\begin{array}{l}\text { SW China/ } \\
\text { SE Asia, } \\
\text { surface } \\
\text { forcing }\end{array}$ \\
\hline \multicolumn{5}{|l|}{$60^{\circ} \mathrm{N}-90^{\circ} \mathrm{N}$} \\
\hline $\mathrm{BC}$ & $0.15 \pm 0.04$ & $-0.22 \pm 0.05$ & $-0.09 \pm 0.03$ & $0.14 \pm 0.05$ \\
\hline $\mathrm{CO}_{2}$ & $0.02 \pm 0.01$ & $0.04 \pm 0.03$ & $-0.02 \pm 0.01$ & $-0.04 \pm 0.03$ \\
\hline Ozone & $0.16 \pm 0.06$ & $1.48 \pm 0.54$ & $-0.06 \pm 0.05$ & $-0.50 \pm 0.46$ \\
\hline Sulfate & $0.10 \pm 0.13$ & $0.14 \pm 0.18$ & $-0.05 \pm 0.11$ & $-0.06 \pm 0.15$ \\
\hline \multicolumn{5}{|l|}{$30^{\circ} \mathrm{N}-60^{\circ} \mathrm{N}$} \\
\hline $\mathrm{BC}$ & $0.41 \pm 0.04$ & $-0.21 \pm 0.02$ & $-0.20 \pm 0.03$ & $0.10 \pm 0.02$ \\
\hline $\mathrm{CO}_{2}$ & $0.26 \pm 0.01$ & $0.67 \pm 0.03$ & $-0.06 \pm 0.01$ & $-0.17 \pm 0.02$ \\
\hline Ozone & $0.18 \pm 0.10$ & $2.92 \pm 1.61$ & $0.03 \pm 0.09$ & $0.41 \pm 1.38$ \\
\hline Sulfate & $0.31 \pm 0.06$ & $0.32 \pm 0.06$ & $-0.09 \pm 0.05$ & $-0.10 \pm 0.05$ \\
\hline \multicolumn{5}{|l|}{$30^{\circ} \mathrm{S}-30^{\circ} \mathrm{N}$} \\
\hline $\mathrm{BC}$ & $0.20 \pm 0.11$ & $-0.09 \pm 0.05$ & $-0.01 \pm 0.10$ & $0.01 \pm 0.04$ \\
\hline $\mathrm{CO}_{2}$ & $-0.16 \pm 0.03$ & $-0.78 \pm 0.13$ & $0.18 \pm 0.02$ & $0.89 \pm 0.11$ \\
\hline Ozone & $-0.28 \pm 0.07$ & $3.42 \pm 0.90$ & $0.21 \pm 0.06$ & $-2.60 \pm 0.77$ \\
\hline Sulfate & $0.27 \pm 0.14$ & $0.27 \pm 0.14$ & $0.14 \pm 0.12$ & $0.14 \pm 0.12$ \\
\hline \multicolumn{5}{|l|}{$30^{\circ} \mathrm{S}-90^{\circ} \mathrm{S}$} \\
\hline $\mathrm{CO}_{2}$ & $-0.06 \pm 0.01$ & $-0.16 \pm 0.04$ & $0.03 \pm 0.01$ & $0.08 \pm 0.03$ \\
\hline \multicolumn{5}{|l|}{$30^{\circ} \mathrm{S}-90^{\circ} \mathrm{N}$} \\
\hline $\mathrm{BC}$ & $0.78 \pm 0.23$ & $-0.44 \pm 0.13$ & $-0.09 \pm 0.19$ & $0.05 \pm 0.11$ \\
\hline Sulfate & $0.64 \pm 0.10$ & $0.67 \pm 0.11$ & $-0.11 \pm 0.09$ & $-0.11 \pm 0.09$ \\
\hline $\mathrm{CO}_{2}$ all latitudes & $-0.02 \pm 0.02$ & $-0.07 \pm 0.07$ & $0.18 \pm 0.02$ & $0.66 \pm 0.06$ \\
\hline
\end{tabular}

US (Figs. 4 and 5). Most tropical forcings lead to similar responses, though significance is generally low except for $\mathrm{BC}$, and responses sometimes vary across the months of the wet season. When forcings are imposed broadly $\left(30^{\circ} \mathrm{S}-90^{\circ} \mathrm{N}\right.$ or globally), BC has a much larger Pacific NW impact than sulfate or $\mathrm{CO}_{2}$ (per unit forcing), while $\mathrm{BC}$ and sulfate have greater impacts on the Eastern US than $\mathrm{CO}_{2}$. Southwest US rainfall is only weakly sensitive to local forcing, but responds strongly to tropical aerosol forcing. Responses to tropical and broad forcings are the same sign. The strong tropical influence on Southwest US precipitation is consistent with paleoclimate studies and sensitivity to tropical ENSO variability (Schubert et al., 2004; Meehl and Hu, 2006).

Sahel rainfall is as or more sensitive to mid-latitude forcing than to local tropical forcing. Tropical and $\mathrm{NH}$ midlatitude BC forcings have opposite impacts (with tropical BC showing impacts that vary between the early and late parts of the season), and hence the response to broadly imposed forcing is greatest for sulfate (and ozone). Substantial Sahel drying for the negative forcing caused by increased sulfate is consistent with other studies linking observed 1970s and 1980s drought with NH sulfate (Kawase et al., 2010; Ackerley et al., 2011; Biasutti and Giannini, 2006; Rotstayn and Lohmann, 2002; Chang et al., 2011).

Since responses are analyzed in terms of precipitation change per unit forcing within individual bands, comparison of the response to broadly imposed forcings with the sum of the responses over the component bands tests the linearity of the precipitation changes. With uniform scaling of current aerosol distributions, our broadly imposed $1.0 \mathrm{~W} \mathrm{~m}^{-2}$ forcings had roughly $0.6 \mathrm{~W} \mathrm{~m}^{-2}$ tropical forcing and $1.7 \mathrm{~W} \mathrm{~m}^{-2}$ Northern extratropical forcing. For the regions examined here, responses to broadly imposed $\mathrm{CO}_{2}, \mathrm{BC}$ or sulfate are nearly always very near the sum of the responses to the identical forcings in the individual bands (Fig. 5; taking into account the applied aerosol forcing distributions). The only exception is the Eastern US response to sulfate, which is slightly larger for the broadly imposed case.

We call the forcing/response relationships derived from these runs Regional Precipitation Potentials (RPPs). These provide a way to estimate the regional precipitation response to a given pattern of forcing, analogous to the 
Regional Temperature Potentials described previously (Shindell and Faluvegi, 2009, 2010; Voulgarakis and Shindell, 2010). While there was some dependence on the type of forcing imposed for the temperature case, the precipitation potentials vary much more strongly with the forcing agent. We examine the applicability of these metrics in the next section.

\subsection{Comparison with historical trends}

We analyzed the response to individual and combined historical forcings in the transient GISS CMIP3 simulations and compared against observations and against estimates obtained using the response per unit latitude band forcing described above (Fig. 5). The left portion of each panel in the figure shows the sensitivity to local forcings as well as three cases where forcings were combined across bands $\left(30^{\circ} \mathrm{S}-\right.$ $90^{\circ} \mathrm{N}$ for $\mathrm{BC}$ and sulfate, all latitudes for $\mathrm{CO}_{2}$ ). The right portion of each panel shows the response in the historical simulations driven by individual and all forcings (open symbols), the observed regional response (far right symbol), and the sum of the RPP (responses per unit local forcing shown on the left) times the actual regional forcings imposed in the historical simulations (solid symbols). The solid and open symbols of the same shape thus show how similar the actual response to temporally and spatially varying forcings is to the response estimated based on the forcing patterns using the RPPs. Comparison of the sensitivities on the left with the historical simulation trends on the right helps reveal how the various forcing agents in various regions influenced the overall trends. Analyses of transient responses used linear regressions, though for impacts of episodic volcanic forcing this may be of limited value. Note that historical WMGHG forcing was $2.3 \mathrm{~W} \mathrm{~m}^{-2}$, so that WMGHG forcing induced changes similar to the $\mathrm{CO}_{2}$-only case in the historical simulations as they are typically about 2.3 times larger.

For regions where observations show substantial trends over the 20th century, aerosol forcing is required to capture those trends (Fig. 5). In particular, for SE Asia, forcing by aerosols (including AIE) induced a strong drying trend that clearly contributes to the "All forcings" response agreeing with observations despite WMGHGs causing a large precipitation increase. Over the 19501998 period, the model's SE Asia "All forcing" trend is $-0.14 \pm 0.07 \mathrm{~mm} \mathrm{day}^{-1}$, in agreement with the observed trend of $-0.30 \pm 0.21 \mathrm{~mm}$ day $^{-1}$, again with aerosol-induced precipitation trends $\left(-0.50 \mathrm{~mm} \mathrm{day}^{-1}\right.$; primarily due to direct effects of local sulfate and remote BC) more than offsetting the impact of WMGHGs $\left(0.40 \mathrm{~mm} \mathrm{day}^{-1}\right)$ (consistent with another recent analysis; Bollasina et al., 2011). For the Sahel, though the model does not fully capture observed drying (which is also seen over the past $50 \mathrm{yr}$; Held et al., 2005), tropical and NH mid-latitude sulfate increases cause substantial drying, while WMGHG, ozone and natural forcings cause little change or precipitation increases.
Comparison with the sensitivity studies provides insight into the GISS model's historical simulations (Fig. 2b) in other regions as well. Pacific Northwest trends are dominated by NH mid-latitude BC forcing, the Eastern US shows comparable magnitude impacts from WMGHG, ozone and aerosols (though BC and sulfate offset one another), while for the Southwest US tropical sulfate caused increased precipitation, offsetting some of the WMGHG (and BC) induced decreases (Figs. 4 and 5). Hence reduction of tropical sulfate not only unmasks WMGHG warming, but may also unmask WMGHG-induced drying of the Southwest US (though reducing Sahel drought risk). Decreased precipitation over In$\mathrm{dia} /$ Bangladesh, which is consistent with observations over the past $50 \mathrm{yr}$ (Wang et al., 2009), is driven largely by aerosol forcing, which outweighs the influence of WMGHG, ozone or natural forcings. Hence over the next several decades, when aerosol forcing is likely to be large, regional precipitation changes in many parts of the world may be strongly influenced by the short-lived climate forcers (as in some projections; Levy et al., 2008).

For ozone changes, the historical response in the transient simulations is statistically indistinguishable from an estimate based on the RPPs (a linear sum of the responses to tropical and $\mathrm{NH}$ mid-latitude forcings times the regional historic forcings) (Fig. 5; open and solid diamonds). Note that high-latitude ozone forcing was not included in the estimate as historical forcing there stems largely from stratospheric depletion. Similarly, responses to all aerosol direct forcings in the transient coupled ocean-atmosphere model are consistent with the RPP-based estimates (comparing the sum of modeled historical $\mathrm{BC}$ and reflective aerosol forcings times the response per unit forcing for $30^{\circ} \mathrm{S}-90^{\circ} \mathrm{N} \mathrm{BC}$ and sulfate forcings) (Fig. 5; open and solid upward pointing triangles). The "All" estimated response is the ADE plus ozone estimates added to the actual historic response to other forcings (AIE, land-use, solar and volcanic; small forcings from stratospheric water vapor and stratospheric ozone are included in the All simulation but are neglected in the estimated response). Non-linearity is seen when all forcings are imposed simultaneously relative to the sum of the individual components (Fig. 5; open and solid squares) for the Pacific NW region, but not for other areas. Hence the RPPs appear to provide a useful metric for regional average precipitation response in this model, and as with the response to broad forcings by a single agent versus the sum of forcings within particular bands, responses appear to be generally linear for combinations of forcing agents.

The response in Asia to aerosol forcing when AIE was included was larger for several cases relative to simulations without AIE (India/Bangladesh response to sulfate, SE Asia response to $\mathrm{BC}$ ), but not significantly so (not shown). An enhanced response in those areas is consistent in direction with the substantial influence of the AIE in the GISS historical simulations (Fig. 5) and with results of another modeling study (Bollasina et al., 2011). The AIE-induced changes in 
the simulations with individual forcing agents are not large enough to fully account for that response, however, suggesting that the net effect may be sensitive to either the mixture of aerosol types or to types not examined in the individual forcing agent runs. That could include organic carbon and/or nitrate aerosols. The impact of regional aerosol indirect cloud effects on precipitation clearly requires a great deal more study, especially as the GISS AR4 model only included a highly parameterized cloud lifetime AIE (and semidirect effects) but not cloud albedo effects, and this will be the topic of work with the new AR5 model which includes a more physically realistic treatment of both types of AIE.

\section{Physical mechanisms}

As noted in Sect. 3.1, forcing by any agent at NH midlatitudes induced a fairly similar pattern of precipitation response in the tropics, with a northward shift of the ITCZ during boreal summer. Similar behavior has been reported in both other comprehensive climate models and in simpler models, and is attributed to thermal forcing and the resultant impact on poleward energy fluxes (Chiang and Bitz, 2005; Kang et al., 2009). Indeed, such modifications of large scale energy fluxes were shown for these simulations in our prior analysis of the impact of regional forcings on temperature (Shindell and Faluvegi, 2009). Forcing by NH mid-latitude ozone is skewed more towards the southern edge of the band than the other forcing agents, which may account for its stronger impact on the tropics. This result highlights how the spatial gradients imposed within the bands and near the latitude band boundaries may have important impacts on the results, and thus merit further study (though we note that the quasi-linearity seen in the simulations with multiple band forcings suggests these edge effects are not too large for aerosols, or at least cancel when realistic perturbations are imposed).

A more detailed examination of the physical mechanisms requires analysis of both local and large-scale circulation processes. A framework for understanding various contributions to regional circulation changes in the tropics was recently presented by Bollasina et al. (2011). In that theoretical framework, which focuses on the Asia/Pacific sector, thermodynamically-induced changes largely follow the tropical mean surface temperature anomaly, in accord with basic physical understanding (e.g. Held and Soden, 2006). The primary thermodynamic impact of warmer tropical mean surface temperatures is to slow the tropical zonal circulation. Dynamic changes (i.e. changes not caused by surface temperature or atmospheric moisture anomalies) are induced much more effectively by forcing gradients as the circulation responds to the resulting regional energy imbalances. Thus aerosols in the Bollasina et al. (2011) analysis, which are primarily cooling agents, by being located primarily in the $\mathrm{NH}$ act to reduce meridional energy gradients and hence substantially slow the merdional circulation while having only a modest effect on the zonal flow. The combination of aerosol and greenhouse gas forcing reflected the large impact of aerosol on meridional circulation and of greenhouse gases on zonal circulation in their model.

We have examined the surface wind and sea-level pressure (SLP) changes induced by the regional forcings in our simulations (Fig. 6). Note that to facilitate comparison of the response to various forcing agents, responses to individual forcing agents are all shown per unit positive forcing (even when the imposed forcing was negative). We find that positive tropical $\mathrm{BC}$ forcing induces a very strong enhancement of the meridional surface winds over the western Indian Ocean, though this is in part reflective of an increasing anticyclonic flow around the Indian subcontinent. There is also a modest enhancement of the equatorial zonal circulation. Positive tropical sulfate forcing induces a similar but weaker meridional response than $\mathrm{BC}$, but causes strong easterly anomalies in the western Pacific and westerly anomalies in the Atlantic and eastern Pacific sectors. These results are somewhat consistent with the framework of Bollasina et al. (2011), especially the zonal flow changes, bearing in mind that they examined the impact of an overall negative aerosol forcing, but our changes in meridional circulation are in general more closely tied to anomalous flow around localized SLP changes.

Not only do local forcings induce these type of tropical responses, but all the NH mid-latitude forcings lead to increased anticyclonic flow around the Indian subcontinent as well. Hence this region is sensitive to both local and remote forcing. The response to remote forcing is similar regardless of the forcing agent, consistent with thermal forcing, while as noted, the response to local forcing is more sensitive to $\mathrm{BC}$ and sulfate than to carbon dioxide, consistent with dynamic forcing. The enhanced anticyclonic flow increases the supply of moisture-laden air flowing from the Indian Ocean to the continent during the monsoon, consistent with the precipitation responses (Fig. 5). In addition to the Indian Ocean sector, there is also a large enhancement of the meridional flow off the west coast of Mexico in response to tropical BC. This appears to strengthen ascent off the coast, reducing the influx of moist marine air into the SW US and accounting for the high sensitivity of that region to tropical BC in particular (Fig. 5). A somewhat similar response is seen for tropical $\mathrm{CO}_{2}$ forcing, which also strengthens the anticyclonic flow here, though the impact of $\mathrm{BC}$ is stronger. In contrast, midlatitude forcing has little impact on circulation in the North American monsoon area. The enhanced response to BC seen in the North American monsoon region is like that seen for the South Asian region, though the latter is even more pronounced, and may reflect the extra energy absorbed within the atmosphere by BC.

Like the tropical responses, extratropical responses are also tied to localized circulation changes. The NH midlatitude response to tropical forcing shows anomalous 
$\mathrm{NH}$ mid-latitude $\mathrm{CO}_{2}$
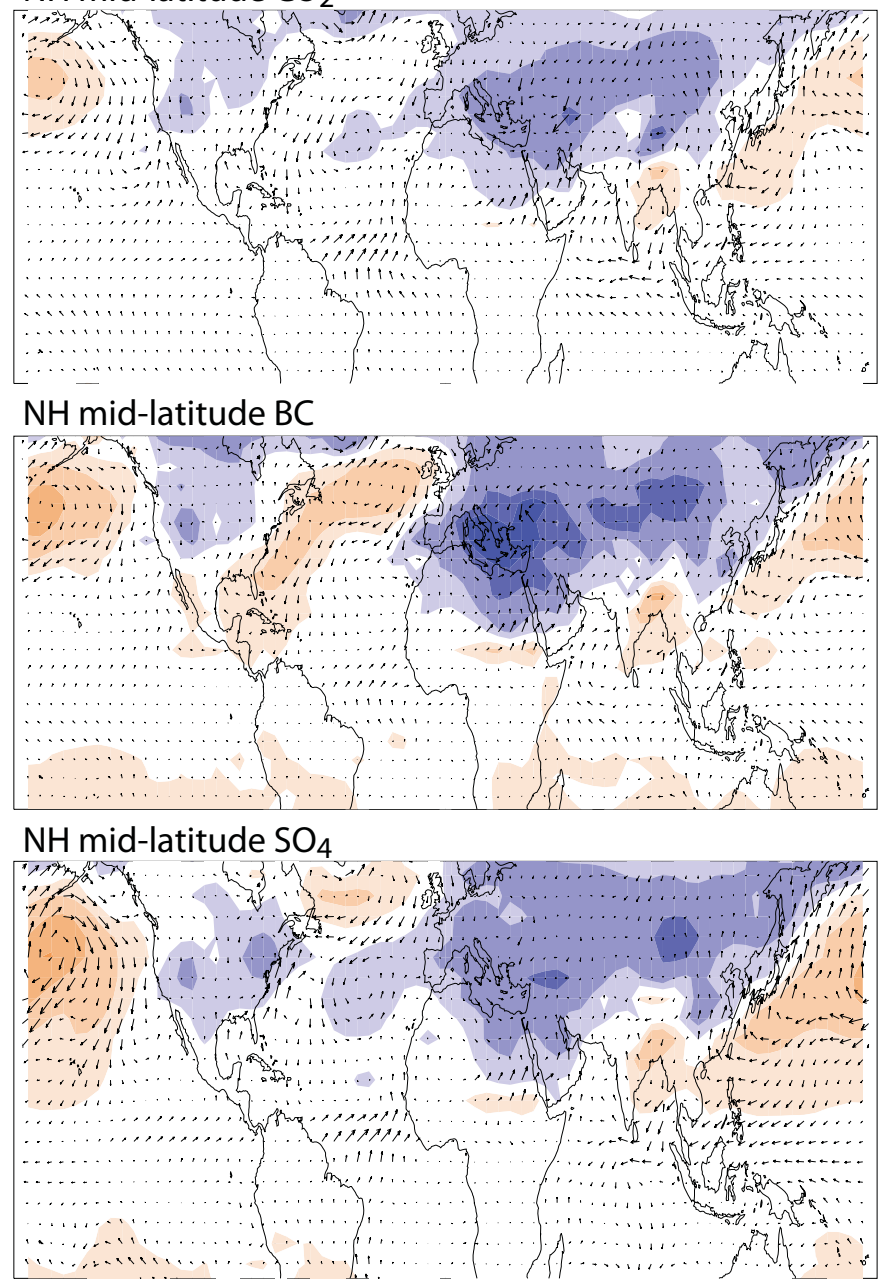

Historical well-mixed greenhouse gases

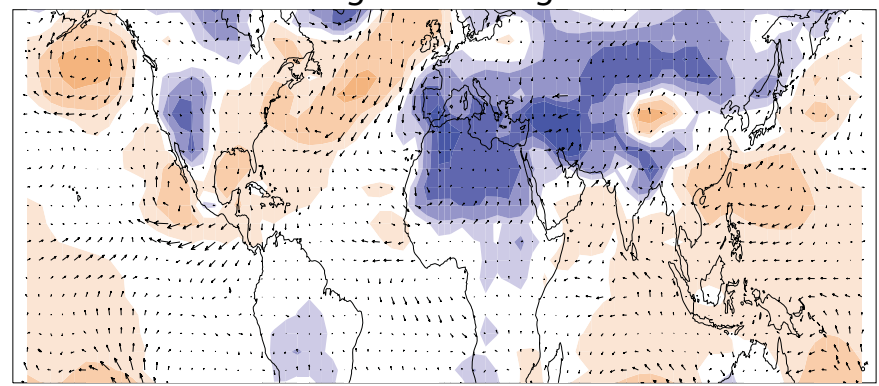

Tropical $\mathrm{CO}_{2}$

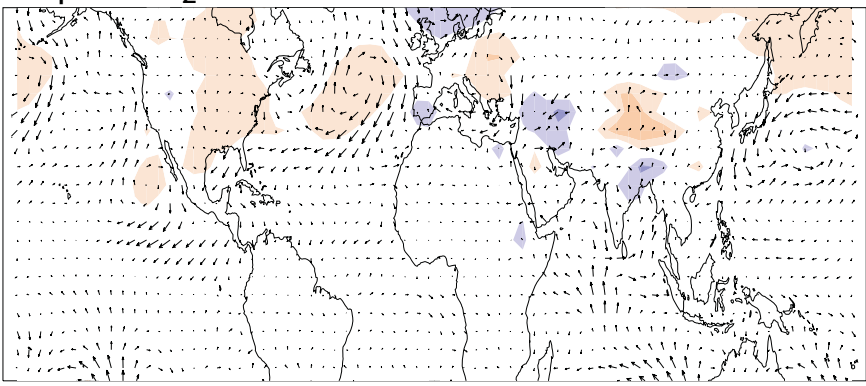

Tropical BC

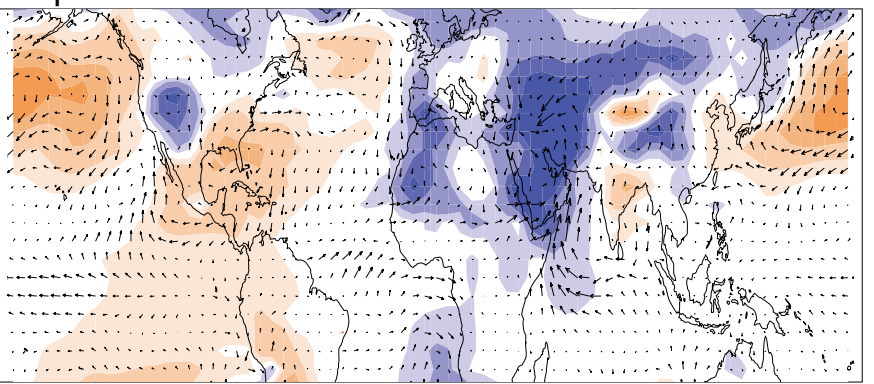

Tropical $\mathrm{SO}_{4}$

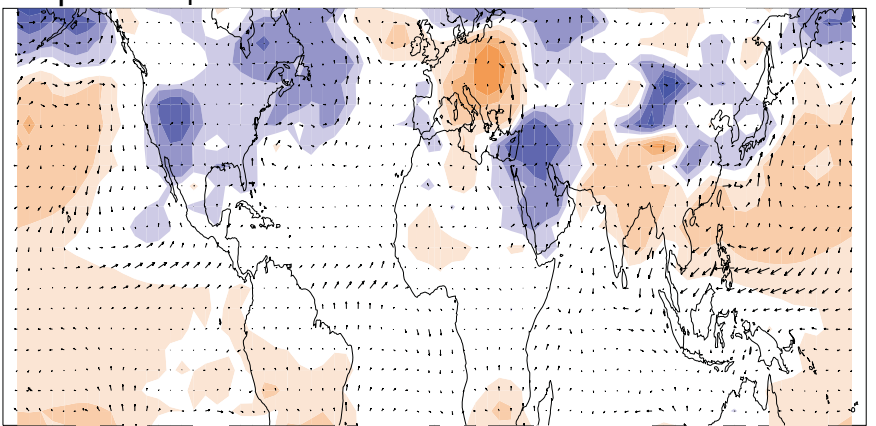

Historical aerosols

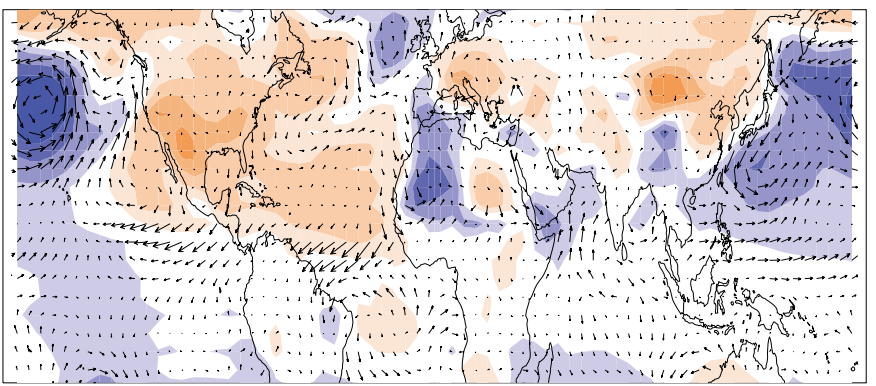

$-.75$

Fig. 6. Sea-level pressure (colors, hPa) and surface wind (vectors) responses per unit positive forcing (top three rows) and in historical simulations (bottom row; greenhouse forcing is positive, net aerosol forcing negative). Wind changes are normalized to show relative geographic variations within a given panel (absolute wind strength changes are closely linked to the magnitude of the SLP anomalies).

circulation around enhanced North Pacific and North Atlantic highs in response to positive forcing by aerosols or $\mathrm{CO}_{2}$ and a dipole with positive pressure anomalies over Eastern Europe and negative anomalies over the Middle East. NH mid-latitude responses over the oceans are similar for posi- tive local NH mid-latitude forcing by various agents, and often for positive tropical forcing as well, suggesting that in these areas positive forcing enhances preexisting circulation patterns regardless of the type of forcing or where the forcing itself is located (although the European sector response 
is dependent upon forcing location). Responses are typically stronger for aerosol forcing than for equivalent $\mathrm{CO}_{2}$ forcing, however, leading to the enhanced sensitivity to broadly distributed aerosol forcing for the Eastern US, for example (Fig. 5). The strong enhancement of the North Pacific high in response to $\mathrm{BC}$, which favors southerly rather than easterly flow off the coast, is consistent with the reduced precipitation reaching the Pacific NW in response to $\mathrm{BC}$ forcing (Fig. 5).

While the tropical responses to $\mathrm{BC}$ are enhanced relative to other forcing agents, this is typically not the case over $\mathrm{NH}$ midlatitudes (other than Europe), where the response to BC very much resembles the response to sulfate, and hence the net aerosol historical impact resembles the sulfate impact (as sulfate forcing is stronger than BC's). Similarly, the historical response over the tropical Atlantic does not follow the pattern of BC-induced changes but instead matches the response to sulfate, especially $\mathrm{NH}$ mid-latitude sulfate.

This suggests that for responses governed primarily by thermodynamic forcing, for which all agents cause similar responses, the larger radiative forcing by sulfate causes its impact to outweigh the impact of BC. This holds for the mid-latitudes, and also for western Africa and the Sahel region, which is strongly affected by the enhanced equatorial north-easterlies induced by negative sulfate forcing (Fig. 6) which lead to substantial drying (Fig. 5; consistent with thermal forcing). In dynamically-driven monsoon systems, BC appears to have an enhanced effectiveness, and it's impacts can be as large as those of even a larger sulfate forcing. Quasi-uniform WMGHG forcing enhances the same NH mid-latitude pre-existing circulation patterns as do aerosols, but has much less impact on the tropical Atlantic or Indian Ocean regions. Ozone forcing, which is much more uniform than aerosol forcing (Fig. 1), has broadly similar effects to WMGHGs in South Asia, suggesting that it does not trigger similar dynamic responses to aerosols. However, its hemispheric asymmetry still leads to large-scale thermal forcing, and it causes a substantial shift in the tropical Atlantic similar to that due to aerosols (Fig. 5).

Thus the meridional circulation anomalies in the Atlantic seem to be most closely tied to large-scale (e.g. interhemispheric) gradients, those in the Indian sector and the North American monsoon region are related to both large-scale and local forcing gradients, while the anomalies in most other regions appear to follow the overall mean forcing magnitude more closely. This suggests that further work exploring the impact of locating forcing gradients at different locations than the bands chosen here would be valuable, especially for better understanding Atlantic and Indian sector responses (though as noted previously, these sum across regions fairly linearly, and meridional gradients are comparably large even for realistic forcings imposed across multiple bands for sulfate and BC (Fig. 1)). Intriguingly, the localized response over the Arabian Sea is stronger for BC, which has very large gradients at these longitudes, while the response in the western Pacific is stronger for sulfate, which has its own greatest gradients at those longitudes (Fig. 1). Hence for dynamical responses, there is a suggestion that the regional forcing pattern may be important.

Our results thus suggest that the gradual shift in aerosol and ozone precursor emissions from $\mathrm{NH}$ mid-latitudes to tropical latitudes that is already underway may have a large impact on future precipitation changes in western Africa and South Asia, as well as on the Southwest US, while NH midlatitude trends will largely follow the total forcing and be less dependent upon its location. Further analyses, including examination of water vapor (Seager et al., 2010) and energy (Muller and O'Gorman, 2011) budgets as well as the role of induced sea-surface temperature changes (Hoerling et al., 2006) may help further elucidate the underlying mechanisms governing the precipitation responses described here.

\section{Discussion and conclusions}

Our regional analyses reveal that precipitation responses to aerosols, and, to a lesser extent, to ozone, are often substantially greater than responses to equivalent $\mathrm{CO}_{2}$ forcing. This result is consistent with initial evidence from the next generation of models (CMIP 5th phase) that have shown a much stronger sensitivity of South Asian and Sahel precipitation to forcing by BC than to equivalent WMGHG forcing (Shindell et al., 2012) and a strong influence of aerosols on Atlantic sector climate trends during the 20th century (Booth et al., 2012). Our finding that the heterogeneity of aerosol and ozone forcing induces substantial changes in circulation is also consistent with other analyses (e.g. Rotstayn and Lohmann, 2002; Ramanathan et al., 2005; Allen et al., 2012). Since the analyses presented here demonstrate that regional response patterns depend on the location of forcing, metrics based on global mean values do not provide useful information on precipitation impacts for inhomogeneous forcings.

Our finding that precipitation responses are often linear with respect to forcings in different locations and by different agents suggests the possibility of providing useful estimates of precipitation responses to regional forcing changes, however. We show how RPPs that vary with forcing agent and location can provide useful information, and in particular that the RPP-based estimates of precipitation changes due to aerosols and ozone gave values that were generally quite consistent with the actual response in full transient climate simulations (Fig. 5). This suggests that it might be possible to rapidly and easily estimate the precipitation changes induced by a particular forcing pattern (i.e. without running a full climate simulation). Such estimates could provide useful guidance for determining which emission scenarios would be most useful to explore with comprehensive climate modeling, for example. Future work with higher resolution models and multi-model intercomparisons are needed to more fully characterize the relationship between localized forcings and precipitation response and the variation of the RPP metric 
across models, as well as the mechanisms responsible. Further work should also investigate the response to forcings imposed at various longitudes.

Disagreement among CMIP3 models' precipitation projections is large over North America, the Sahel, and much of South and East Asia, where inhomogeneous forcing agents have a large impact, but small over Southern Africa, the Mediterranean, the North Atlantic, and high latitudes, where their impact does not appear to be as enhanced. Differing representations of inhomogeneous forcing may thus contribute substantially to divergence in projected precipitation in the former regions, consistent with a recent analysis of global scale precipitation projections (Pendergrass and Hartmann, 2012).

An improved understanding of aerosol and ozone influences on regional precipitation leads to a more nuanced view of the interplay between air quality policies and climate. For reflective aerosols in particular, reduced emissions improve air quality but augment global warming. This creates a perception of sulfur controls, for example, having air quality benefits but climate disbenefits (Ramanathan and Xu, 2010; Raes and Seinfeld, 2009). The response of Sahel rainfall to decreased sulfate is a clear example of reduced $\mathrm{NH}$ sulfur emissions alleviating drought (after the $\mathrm{NH}$ emissions first caused much of the drought). Thus, although those sulfur reductions unmasked greenhouse warming, and hence were harmful from a global mean temperature perspective, they were extremely beneficial for Sahel precipitation.

Our results thus imply that policies to address air quality, or policies to address climate change that have a substantial impact on short-lived climate forcers (e.g. fuel switching from coal to gas), may have large impacts on regional water supplies that are not proportional to their effect on global mean surface temperature. From an air quality perspective, any reduction in emissions of aerosol or ozone precursors is beneficial. Our analysis suggests that for emissions leading to positive forcing, and even for cooling aerosols such as sulfate or organic carbon (OC), reductions may be beneficial for climate when considering precipitation in addition to temperature, since disruption of traditional hydrologic patterns for which agriculture and water systems are optimized tends to be harmful in the net. This suggests a higher priority should be placed on strategies that reduce sulfur and OC than might otherwise have been done, as well as reinforcing the evidence that reducing BC and ozone precursors is beneficial for mitigating climate change impacts. Our results also imply that international cooperation is essential to mitigate hydrologic cycle disruptions, as responses are often greater for remote forcing than for local forcing.

\section{Appendix A}

\section{Results for October to April}

We concentrated our analyses on May-September. From October-April, modest responses were found in several cases in the regions we focus on. The only statistically significant response for India/Bangladesh is a slight increase in response to $30^{\circ} \mathrm{S}-90^{\circ} \mathrm{N}$ sulfate positive forcing $\left(0.04 \pm 0.02 \mathrm{~mm} \mathrm{day}^{-1}\right.$ per $\left.\mathrm{W} \mathrm{m}^{-2}\right)$. Hence the aerosols appear to have a much weaker impact during this season in this region than in May-September. For SE Asia, both BC and sulfate induce precipitation increases, with tropical forcings having the largest impacts (tropical ozone has a substantial impact as well). When imposed broadly $\left(30^{\circ} \mathrm{S}-90^{\circ} \mathrm{N}\right)$, the increases in responses to $\mathrm{BC}$ and sulfate are $0.29 \pm 0.12$ and $0.10 \pm 0.06 \mathrm{~mm} \mathrm{day}^{-1}$ per $\mathrm{W} \mathrm{m}^{-2}$, respectively, far more than the SE Asia $0.02 \pm 0.01 \mathrm{~mm} \mathrm{day}^{-1}$ per $\mathrm{W} \mathrm{m}^{-2}$ response to global $\mathrm{CO}_{2}$. In contrast, during May-September, the impacts of broadly imposed aerosols and $\mathrm{CO}_{2}$ were of comparable magnitude but opposite sign. The distinctly different behavior for India/Bangladesh and SE Asia during these months relative to May-September suggests a response governed by different mechanisms than the boreal summer monsoon shift.

For the Southwest US, October-April responses to tropical ozone and sulfate are significant, with both causing decreased precipitation $(-0.08 \pm 0.05$ and $-0.14 \pm 0.10 \mathrm{~mm} \mathrm{day}^{-1}$ per $\mathrm{Wm}^{-2}$, respectively). The Eastern US shows increased precipitation in response to tropical ozone $\left(0.07 \pm 0.03 \mathrm{~mm} \mathrm{day}^{-1}\right.$ per $\left.\mathrm{W} \mathrm{m}^{-2}\right)$ or $30^{\circ} \mathrm{S}-$ $90^{\circ} \mathrm{N} \mathrm{BC}\left(0.16 \pm 0.09 \mathrm{~mm} \mathrm{day}^{-1}\right.$ per $\left.\mathrm{W} \mathrm{m}^{-2}\right)$, similar to the response to global $\mathrm{CO}_{2}\left(0.10 \pm 0.01 \mathrm{~mm} \mathrm{day}^{-1}\right.$ per $\left.\mathrm{W} \mathrm{m}^{-2}\right)$. The Pacific NW shows significantly decreased precipitation in response to $\mathrm{BC}$ imposed broadly or at $\mathrm{NH}$ mid-latitudes. This response, along with a modest precipitation decrease for negative sulfate forcing, appears to dominate the historical response, outweighing increases in precipitation due to WMGHG and ozone forcings. There are almost no statistically significant responses for the Sahel during October-April, either for individual agents in particular bands or for any of the historical simulations. The modest responses in October-April relative to May-September in most of these areas justify the focus on the latter season.

\section{Appendix B}

\section{Time dependence of response}

Looking at transient behavior in first $40 \mathrm{yr}$ of the individual localized forcing runs we find that the initial response is generally indistinguishable from the equilibrium response. The only clear exception is the South Asian monsoon response to tropical $\mathrm{BC}$ and sulfate, for which the shift in precipitation 
away from India and into SE Asia in response to positive forcing (Fig. 2 j, h) takes roughly $7 \mathrm{yr}$ to be realized. Our results appear to differ somewhat from a prior study (Andrews et al., 2010), which found a distinct separation between fast atmospherically driven and slow global temperature change driven precipitation responses to forcing. However, their study examined only the global scale, and hence included more ocean than land areas, while we focus on land areas. As seen in Fig. 2, changes over the ocean are larger than those over land, so would dominate at the global scale and many of the regional changes we examine are clearly the result of large scale shifts in atmospheric circulation rather than changes in overall mean rainfall.

Acknowledgements. The authors thank NASA's Modeling and Analysis Program for funding.

Edited by: B. Stevens

\section{References}

Ackerley, D., Booth, B. B. B., Knight, S. H. E., Highwood, E. J., Frame, D. J., Allen, M. R., and Rowell, D. P.: Sensitivity of 20th Century Sahel Rainfall to Sulfate Aerosol and $\mathrm{CO}_{2}$ Forcing, J. Climate, 24, 4999-5014, 2011.

Allen, R. J., Sherwood, S. C., Norris, J. R., and Zender, C. S.: Recent Northern Hemisphere tropical expansion primarily driven by black carbon and tropospheric ozone, Nature, 485, 350-354, 2012.

Andrews, T., Forster, P. M., Boucher, O., Bellouin, N., and Jones, A.: Precipitation, radiative forcing and global temperature change, Geophys. Res. Lett, 37, L14701, doi:10.1029/2010GL043991, 2010.

Biasutti, M. and Giannini, A.: Robust Sahel drying in response to late 20th century forcings, Geophys. Res. Lett, 33, L11706, doi:10.1029/2006GL026067, 2006.

Bollasina, M. A., Ming, Y., and Ramaswamy, V.: Anthropogenic Aerosols and the Weakening of the South Asian Summer Monsoon, Science, 334, 502-505, 2011.

Booth, B. B. B., Dunstone, N. J., Halloran, P. R., Andrews, T., and Bellouin, N.: Aerosols implicated as a prime driver of twentiethcentury North Atlantic climate variability, Nature, 484, 228-232, 2012.

Chang, C.-Y., Chiang, J. C. H., Wehner, M. F., Friedman, A., and Ruedy, R.: Sulfate aerosol control of Tropical Atlantic climate over the 20th century, J. Climate, 24, 2540-2555, 2011.

Chiang, J. C. H., and Bitz, C. M.: Influence of high latitude ice cover on the marine Intertropical Convergence Zone, Clim. Dynam., 25, 477-496, 2005.

Chung, S. H. and Seinfeld, J.: Climate response of direct radiative forcing of anthropogenic black carbon, J. Geophys. Res., 110, D11102, doi:10.1029/2004JD005441, 2005.

Fuglestvedt, J. S., Shine, K. P., Berntsen, T., Cook, J., Lee, D. S., Stenke, A., Skeie, R. B., Velders, G. J. M., and Waitz, I. A.: Transport impacts on atmosphere and climate: Metrics, Atmos. Environ., 44, 4648-4677, 2010.
Hansen, J., Sato, M., Ruedy, R., Kharecha, P., Lacis, A., Miller, R., Nazarenko, L., Lo, K., Schmidt, G. A., Russell, G., Aleinov, I., Bauer, S., Baum, E., Cairns, B., Canuto, V., Chandler, M., Cheng, Y., Cohen, A., Del Genio, A., Faluvegi, G., Fleming, E., Friend, A., Hall, T., Jackman, C., Jonas, J., Kelley, M., Kiang, N. Y., Koch, D., Labow, G., Lerner, J., Menon, S., Novakov, T., Oinas, V., Perlwitz, Ja., Perlwitz, Ju., Rind, D., Romanou, A., Schmunk, R., Shindell, D., Stone, P., Sun, S., Streets, D., Tausnev, N., Thresher, D., Unger, N., Yao, M., and Zhang, S.: Dangerous human-made interference with climate: a GISS modelE study, Atmos. Chem. Phys., 7, 2287-2312, doi:10.5194/acp-72287-2007, 2007a.

Hansen, J., Sato, M., Ruedy, R., Kharecha, P., Lacis, A., Miller, R. L., Nazarenko, L., Lo, K., Schmidt, G. A., Russell, G., Aleinov, I., Bauer, S., Baum, E., Cairns, B., Canuto, V., Chandler, M., Cheng, Y., Cohen, A., Genio, A. D., Faluvegi, G., Fleming, E., Friend, A., Hall, T., Jackman, C., Jonas, J., Kelley, M., Kiang, N. Y., Koch, D., Labow, G., Lerner, J., Menon, S., Novakov, T., Oinas, V., Perlwitz, Ja., Perlwitz, Ju., Rind, D., Romanou, A., Schmunk, R., Shindell, D., Stone, P., Sun, S., Streets, D., Tausnev, N., Thresher, D., Unger, N., Yao, M., and Zhang, S.: Climate simulations for 1880-2003 with GISS modelE, Clim. Dynam., 29, 661-696, 2007b.

Held, I. M. and Soden, B. J.: Robust responses of the hydrological cycle to global warming, J. Climate, 19, 5686-5699, 2006.

Held, I. M., Delworth, T. L., Lu, J., Findell, K. L., and Knutson, T. R.: Simulation of Sahel drought in the 20th and 21st centuries, P. Natl. Acad. Sci., 102, 17891-17896, 2005.

Hoerling, M. P., Hurrell, J., Eischeid, J., and Phillips, A.: Detection and Attribution of Twentieth-Century Northern and Southern African Rainfall Change, J. Climate, 19, 3989-4008, 2006.

Hulme, M., Osborn, T. J., and Johns, T. C.: Precipitation sensitivity to global warming: Comparison of observations with HadCM2 simulations, Geophys. Res. Lett, 25, 3379-3382, 1998.

Kang, S. M., Frierson, D. M. W., and Held, I. M.: The tropical response to extratropical thermal forcing in an idealized GCM: the importance of radiative feedbacks and convective parameterization, J. Atmos. Sci., 66, 2812-2827, 2009.

Kawase, H,, Abe, M., Yamada, Y., Takemura, T., Yokohata, T., and Nozawa, T.: Physical mechanism of long-term drying trend over tropical North Africa, Geophys. Res. Lett., 37, L09706, doi:10.1029/2010GL043038, 2010.

Kawase, H., Takemura, T., and Nozawa, T.: Impact of carbonaceous aerosols on precipitation in tropical Africa during the austral summer in the twentieth century, J. Geophys. Res., 116, D18116, doi:10.1029/2011JD015933, 2011.

Levy, H., Schwarzkopf, M. D., Horowitz, L., Ramaswamy, V., and Findell, K. L.: Strong sensitivity of late 21 st century climate to projected changes in short-lived air pollutants, J. Geophys. Res., 113, D06102, doi:10.1029/2007JD009176, 2008.

Meehl, G. A. and Hu, A.: Megadroughts in the Indian monsoon region and southwest North America and a mechanism for associated multi-decadal Pacific sea surface temperature anomalies, J. Climate, 19, 1605-1623, 2006.

Meehl, G. A., Stocker, T. F., Collins, W. D., Friedlingstein, P., Gaye, A. T., Gregory, J. M., Kitoh, A., Knutti, R., Murphy, J. M., Noda, A., Raper, S. C. B., Watterson, I. G., Weaver, A. J., and Zhao, Z.C.: Global Climate Projections, in: Climate Change 2007: The Physical Science Basis. Contribution of Working Group I to the 
Fourth Assessment Report of the Intergovernmental Panel on Climate Change, edited by: Solomon, S., Qin, D., Manning, M., Chen, Z., Marquis, M., Averyt, K. B., Tignor, M., and Miller, H. L., Cambridge Univ. Press, Cambridge, UK and New York, NY, USA, 2007.

Meehl, G. A., Arblaster, J. M., and Collins, W. D.: Effects of Black Carbon Aerosols on the Indian Monsoon, J. Climate, 21, 28692882, 2008.

Ming, Y. and Ramaswamy, V.: Nonlinear Climate and Hydrological Responses to Aerosol Effects, J. Climate, 22, 1329-1339, 2009.

Muller, C. J. and O'Gorman, P. A.: An energetic perspective on the regional response of precipitation to climate change, Nat. Clim. Change, 1, 266-271, 2011.

Pendergrass, A. G. and Hartmann, D. L.: Global-mean precipitation and black carbon in AR4 simulations, Geophys. Res. Lett., 39, L01703, doi:10.1029/2011GL050067, 2012.

Raes, F. and Seinfeld, J. H.: New Directions: Climate change and air pollution abatement: A bumpy road, Atmos. Environ., 43, 51325133, 2009.

Ramanathan, V. and Carmichael, G.: Global and regional climate changes due to black carbon, Nat. Geosci., 1, 221-227, 2008.

Ramanathan, V. and Xu, Y.: The Copenhagen Accord for limiting global warming: Criteria, constraints, and available avenues, $\mathrm{P}$. Natl. Acad. Sci., 107, 8055-8062, 2010.

Ramanathan, V., Chung, C., Kim, D., Bettge, K., Buja, L., Kiehl, J. T., Washington, W. M., Fu, Q., Sikka, D. R., and Wild, M.: Atmospheric Brown Clouds: Impacts on South Asian Climate and Hydrological Cycle, P. Natl. Acad. Sci., 102, 5326-5333, 2005.

Rotstayn, L. D. and Lohmann, U.: Tropical Rainfall Trends and the Indirect Aerosol Effect, J. Climate, 15, 2103-2116, 2002.

Schubert, S. D., Suarez, M. J., Pegion, P. J., Koster, R. D., and Bacmeister, J. T.: On the cause of the 1930s Dust Bowl, Science, 303, 1855-1859, 2004.

Seager, R., Naik, N., and Vecchi, G. A.: Thermodynamic and Dynamic Mechanisms for Large-Scale Changes in the Hydrological Cycle in Response to Global Warming, J. Climate, 23, 46514668, 2010.
Shindell, D. and Faluvegi, G.: Climate response to regional radiative forcing during the 20th century, Nat. Geosci., 2, 294-300, 2009.

Shindell, D. and Faluvegi, G.: The net climate impact of coal-fired power plant emissions, Atmos. Chem. Phys., 10, 3247-3260, doi:10.5194/acp-10-3247-2010, 2010.

Shindell, D., Schulz, M., Ming, Y., Takemura, T., Faluvegi, G., and Ramaswamy, V.: Spatial scales of climate response to inhomogeneous radiative forcing, J. Geophys. Res., 115, D19110, doi:10.1029/2010JD014108, 2010.

Shindell, D., Kuylenstierna, J. C. I., Vignati, E., Van Dingenen, R., Amann, M., Klimont, Z., Anenberg, S. C., Muller, N. Z., Janssens-Maenhout, G., Raes, F., Schwartz, J., Faluvegi, G., Pozzoli, L., Kupiainen, K., Hoglund-Isaksson, L., Emberson, L., Streets, D., Ramanathan, V., Hicks, K., Oanh, N. T. K., Milly, G., Williams, M., Demkine, V., and Fowler, D.: Simultaneously Mitigating Near-Term Climate Change and Improving Human Health and Food Security, Science, 335, 183-189, 2012.

Shine, K. P., Fuglestvedt, J. S., Hailemariam, K., and Stuber, N.: Alternatives to the Global Warming Potential for Comparing Climate Impacts of Emissions of Greenhouse Gases, Clim. Change, 68, 281-302, 2005.

Takemura, T., Nozawa, T., Emori, S., Nakajima, T. Y., and Nakajima, T.: Simulation of climate response to aerosol direct and indirect effects with aerosol transport-radiation model, J. Geophys. Res., 110, D02202, doi:10.1029/2004JD005029, 2005.

Voulgarakis, A. and Shindell, D. T.: Constraining the Sensitivity of Regional Climate with the Use of Historical Observations, J. Climate, 23, 6068-6073, 2010.

Wang, C., Kim, D., Ekman, A. M. L., Barth, M. C., and Rasch, P. J.: Impact of anthropogenic aerosols on Indian summer monsoon, Geophys. Res. Lett., 36, L21704, doi:10.1029/2009GL040114, 2009. 